\section{REFORMA DO CÓDIGO COMERCIAL}

\section{Florêncio de Abreu}

Plano do "Esbôço" para o anteprojeto. Correntes contrárias: código de obrigacões, digo de direito privado, o direito comercial como direito da emprêsa. Distribuição da matéria: os títulos de crédito, as sociedades, a conta de participação.

1. Coincide a comemoração do cinqüentenário da Faculdade de Direito da Universidade do Rio Grande do Sul com a foculdade de do Código Comercial brasileiro. Vem, assim, ao propósito centenário tema atinente à reforma, ou, mais exatamente proposito abordar ploma legislativo, reforma, ou, mais exatamente, atualização dêsse diploma legislativo, sem dúvida de todo conveniente, senão necessária.

Monumento de saber jurídico para ou necessária. cial há sofrido, durante écódigo Comerfial há sofrido, durante esse período de sua existência, inúmeras reformas parciais, que o têm reduzido a retalhos, em holocausto às exigências da evolução da ciência jurídica, especialmente no campo do direito comercial em no campo do vimento dos fenômenosonancia com o ritmo acelerado do desenvolvimento dos fenômenos econômicos. Relativamente incólume, mas nente a ditenas a Parte II, concernente ao direito marítimo. A Parte III, sôbre as quebras, foilhe amputada e substituída por A Desapareceu especiais sôbre a falência. sistemas de anização judiciária. Na Parte I, foram revogados Capítulo I do Título XIII, sôbre hipoteca, o Capítulo II do Título XV sôbre as sociedades anônimas, e o Título XVI sôbre as letras de cambio, notas promissórias e créditos mercantis, além dos acréscimos e modificações a outros Títulos dessa Parte I. Como observa Carvalho de Mendonça, cada uma dessas novas leis sôbre matéria de comércio é golpe no Código, que foi "perdendo a unidade do seu conjunto e a harmonia de suas disposições".

Impondo-se destarte a atualização do Código Comercial, o eminente ministro Adroaldo M. da Costa dirigiu-se a institutos de cultur jurídica e a especialistas, solicitando sugestões a fim de submetê-las à apreciação da douta comissão incumbida de elaborar o anteprojeto de Código Comercial. Foram as sugestões apresentadas em número insignificante; mas; tendo sido lembrada a conveniência da organização prévia de alguma coisa de concreto para servir de base à formulação de sugestões, alvitres, ou emendas, conferiu-nos o ministro êsse trabalho preparatório de coligir e reunir a grande massa de material esparso e distribuí-lo e agrupá-lo de conformidade com os respectivos institutos, formando-se, assim, um esbôço de código comercial.

Como explicamos em nota preliminar, no "Esbôço" foram coordenados para êsse fim, os dispositivos do Projeto do insigne INGLEZ DE SOUZA, do Projeto de 1927, elaborado pela ilustre comissão do Senado, e do Substitutivo do desembargador VIEIRA FERREIRA atualizados mediante a consolidação das leis de carácter mercantil promulgados depois de 1930. Utilizámos ainda, no que fôsse oportuno adatar ao direito positivo brasileiro, o projeto de Código Comercial para a Itália, elaborado por uma comissão constituída de alguns dos mais notáveis especialistas italianos (Sraffa, Bolaffio, Bonelli, Scialoja, Rocco, Navarrini, Asquini e outros), presidida pelo grande VIVANTE, e ainda a "lei uniforme" de Genebra sôbre a cambial e o cheque, e o recente Código Civil italiano, que absorveu a maior parte da matéria, nitidamente comercial, então regulada pelo Códice di Comercio, ora revogado. Projetam, assim, essas altas fontes, sôbre o "Esbôço", uma autoridade que falece ao seu obscuro organizador.

2. Divulgado o "Esbôço", várias correntes de opinião surgiram em tôrno da idéia da elaboração de um anteprojeto de código comercial. Dessas correntes destaca-se a que preconiza de preferência a promulgação de um "código de obrigações", a exemplo da Suiça, compreendendo as obrigações civis e comerciais; e, ao lado dêsse código, a promulgação do "estatuto" dos comerciantes ou das emprêsas mercantis, abrangendo o restante da matéria tradicionalmente considerada pertinente ao direito comercial.

Cumpre, porém, não perder de vista que o "Código Suiço de Obrigaçöes" é o fruto de um movimento político, num dado momento histório do povo helvético. A Constituição suiça de 1848, que transformara em Estado federativo a antiga Confederação dos cantões, nada dispunha sôbre a unificação total, ou parcial, do direito privado; mas, desde 1798, os Conselhos da República preconizavam a idéia de uma legislação civil uniforme para todo o país. O surto considerável do seu comércio e da sua indústria, o desenvolvimento sempre crescente das relações e das permutas entre os cantões e dêstes com o exterior fizeram nascer a convicção de que a diversidade de leis (um inextricável dédalo de vinte e seis códigos, - na expressão de Rossel - para reger a pequena população de 2.500 .000 habitantes) era sobremodo prejudicial aos interêsses vitais do país. Entretanto, "os particularismos 
locais, as rivalidades cantonais, as apreensões do povo ditadas pelo receio de mudanças, a indiferença suscitada pelo amor-próprio de certos cantões, que acreditavam possuir uma legislação superior àquela com que os ameaçam", eram poderosos fatôres que conspiravam con tra a projetada centralização.

Teve, não obstante, o Conselho Nacional a esperança de conseguir a unificação, pelo menos, do direito das obrigações; e, convocados os cantões em conferência, acordaram afinal, não sem prolongados debates, na elaboração de uma lei geral sôbre a referida matéria. Preparado por Munzinger, em 1871, foi o projeto do Código de Obrigações convertido em lei dez anos depois e sòmente pôsto em vigor em 10 de janeiro de 1883 . Obteve-se assim, por óbvios motivos de ordem política, a união mais estreita entre as diversas partes do país união que, sem dúvida, a codificação federal realizaria; e, na observação da "M"ensagem" dirigida pelo Conselho Federal à Assembléia Federal ao propósito do projeto de código civil, a promulgação do código unitário de obrigações seguiu a linha de menor resistência, por isso que não havia sensíveis divergências entre as leis dos cantões dotados de um direito de obrigações codificado.

Assim, sem um motivo político ou de utilidade prática, mas por simples razão de ordem técnica ou de doutrina, aliás controvertida, seria aconselhável romper agora a tradição brasileira e mutilar a obra de CLóVIS? Em meio o labirinto de inúmeras leis dispersas, que tortura os próprios profissionais, o que se reclama se afigura pràticamente mais útil é sem dúvida dotar o país de uma codificação atualizada das leis comerciais, em substituição ao atual Código, quase inexistente.

3. Colimando a unificação do direito positivo das obrigações civis e comerciais, foi em 1941 elaborado por três eminentes civilistas OROZIMBO NONATO, PHILADELPHO AZEVEDO e HAHNEMANN GUIMARÃES - um anteprojeto de Código de obrigaçóes, compreendendo apenas a parte geral. Trabalho de grande mérito, não se poderia afirmar, em tese, que seria êle de to grande mérito, não " "Esbôço". Nas palavras preliminares co todo incompatível com car aloumas dive procuramos justificar algumas divergências entre êste e os Projetos que lhe serviram de fonte, salientamos que as regras e disposições de direito civil, que regulam a capacidade, os contratos, as obrigações não são mero subsídio da lei comercial, mas pressuposto desta. Deixou, portanto, "Esbôço" de parte neste ponto, o Projeto INGLEZ DE SOUZA, que abrange tôda a matéria que o Código Civil regulou, e pouco também colheu do Projeto do Senado, pois êste também insere copiosamente disposições de natureza civil, transcrevendo aliás, literalmente, grande número de artigos do Código Civil.

Não há negar que a parte geral da matéria atinente às obrigações forma um cómplexo de princípios aplicáveis aos dois campos de direito privado. De sorte que, pondo de lado os dispositivos que ambos os Projetos inserem na parte nuclear das obrigações, o "Esbôco" apenas insere o resíduo inevitável de quinze artigos, signanter sôbre a presunção de onerosidade e solidariedade das obrigaçôes comerciais, sôbre a proibição do anatonismo, salvo acumulação de juros vencidos aos saldos líquidos de contas correntes, sôbre a interpretação das cláusulas dos contratos mercantis e sôbre a prova dos livros dos comerciantes. Na parte especial restringe-se o "Esbôço" a regular os contratos tipicamente mercantis, como o estimatório, o de fornecimento, a comissão, a expedição, os transportes terrestres, a conta corrente, os contratos bancários, o depósito nos armazéns e trapiches, a hospedagem e os espetáculos públicos. Dos chamados híbridos, como o mandato e a compra e venda de bens móveis, o "Esbôço" apenas atende às alterações que êsses contratos sofrem nas relações comerciais, especialmente no tocante à venda sôbre documentos, com pagamento contra documentos e com reserva de domínio e bem assim ao reporte. No sistema brasileiro o seguro é civil, exceto o marítimo e os que têm por objeto ato, coisa ou estabelecimento de comércio.

Além de eliminar o inconveniente de uma grande massa inútil de disposições paraleías num e noutro código, o "Esbôço" aproximase sensivelmente da solução preconizada pelos prosélitos da unificação do direito das obrigações.

4. Uma outra corrente de opinião, e ao que parece de menor densidade entre nós, é a que prefere a unificação integral do direito privado. Já o grande TEIXEIRA DE FREITAS, como é amplamente sabido, considerava arbitrária a separaça das leis comerciais das civis; e mais tarde, confiada pelo Govêrno Federal a INGLEZ DE SOUZA a elaboração de um projeto de código comercial, o ilustre jurista apresentava, em 1912, dois projetos, o de código comercial e um outro de emendas tendentes à transformá-lo em código de direito privado. $O$ Senado Federal, porém, rejeitou o projeto de unificação, refletindo assim o pensamento jurídico brasileiro.

Essa corrente, porém, sente-se hoje sobremodo fortalecida com a promulgação do Código Civil italiano, que reúne em seu texto matérias de direito civil, de direito comercial e até do trabalho, sem que se possa bem estabelecer uma séria correspondência entre essa unificação material de conteudo e a sua organicidade ou unidade jurídica. Afirmase, como diz o professor Ferrara Jr., e logo se presume que a supressão do código comercial foi devido a um verdadeiro "colpo di testa legislativo", efetuado por motivos de ordem política, e com a preocupação de imprimir a essa codificação uma "impostazione nuova". Patenteiase de um lado, a aversão pelas palavras comércio e comerciante, consideradas próprias da economia capitalista e, de outro lado, a exigência de pôr mormente em evidência o trabalho, tendo na devida conta a organização corporativa do regímen nacional fascista. 
Um código único de direito privado, pretendendo a fusão das matérias de direito civil e de direito comercial é contrário à lei evolutiva no sentido da diferenciação, da especialização, para fazer coexistir num mesmo corpo de leis fenômenos tão diversos, como os de ordem familiar e sucessória e os de ordem comercial e industrial. E' frisante o exemplo que nos fornecem no momento os Estados Unidos, onde o Instituto Americano de Dïreito e a Conferência Nacional dos Comissários para leis uniformes nos Estados estão elaborando um código comercial uniforme, e pretendem depois organizar com o mesmo objetivo um código civil. ' $E$ ' propósito ainda daquelas entidades conseguir a uniformização do direito comercial mediante a adoção de um código único para as nações americanas. E não deixa de ser de muito interêsse essa uniformização do direito comercial, atenta a índole expansionista do comércio, e sòmente possível em relação a êsse ramo do direito privado, cujas tendências para a unidade e universalização constituem uma de suas características, em contraste com a índole territorial, conservadora e tradicionalista do direito civil.

5. Uma terceira corrente entende que a reforma do Código deve sistematizar a matéria de direito comercial como direito da emprêsa. A novidade foi na Itália desde 1926, sustentada por MOSSA, para quem o direito comercial é "a disciplina das organizações comerciais, o direito das emprêsas", em contraposição ao direito civil, "que deveria limitar-se a regular os atos não organizados pela emprêsa”. E, em apoio da nova doutrina, FINZI observa que, não havendo verdadeiramente comércio onde falte a emprêsa, ou o respectivo estabelecimento, "o comércio não é sòmente o fenômeno das trocas, porém, antes, a organização para as trocas". O código que concretizasse na prática a doutrina em referência, teria a inestimável vantagem de evitar a insuperável dificuldađe oriunda da classificação dos atos de comércio.

Trilhando o caminho indicado pela nova doutrina, o "Comitato Ministeriale" apresentava na Itália, em 1940, um projeto do código comercial para aquêle país, imprimindo ao direito comercial a estrutura de direito das emprêsas comerciais. $O$ projeto, porém, não vingou. A codificação não poderia abranger tôdas as emprêsas, pois muitas existem que não são comerciais, resultando daí a necessidade de conceituar as de carácter mercantil. Essa conceituação, como já advertimos noutra oportunidade, só poderá ser objetiva e não se evitaria assim o escolho da definição ou enumeração dos atos de comércio. O novo Código Civil italiano, para distinguir as emprêsas comerciais, careceu de classificá-las objetivamente, segundo as suas atividades. Distribuiu-as por cinco classes ou categorias, segundo exercitem: 1) uma atividade industrial para a produção de bens ou de serviços; 2) uma atividade intermediária na circulação dos bens; $3 .^{\circ}$ ) uma atividade de transporte por terra, água ou ar; $4 .^{\circ}$ ) uma atividade bancária ou de seguros; $5 .^{\circ}$ ) outras atividades auxiliares das precedentes. Foi êsse

o critério adotado pelo "Esbôço", que, todavia, desceu a algumas particularidades no intuito de bem esclarecer a aplicação prática da lei comercial.

Por outro lado, decorrem da organização das emprêsas (comerciais, ou não) importantes relações internas entre estas e os seus empregados ou prepostos, cuja disciplina escapa ao âmbito do direito comercial para incidir no do direito do trabalho, que, no sistema brasileiro, é objeto de legislação especial.

6. No tocante à distribuição da matéria no "Esbôço", taxou-se de "violência" a inserção dos títulos de crédito sob a rubrica das coisas, e embargou-se a inclusão das sociedades em conta de participação sob a das pessoas.

Cumpre desde logo frisar que foi em consonância com os Projetos brasileiros que os títulos de crédito ficaram subordinados ao Livro concernente às coisas. Aliás, como já tivemos a oportunidade de observar, êsses Projetos estão, neste ponto, dentro da orientação do nosso eminente CARVALHO DE MENDONÇA e do insigne VIVANTE, cujos tratados inserem tais títulos na parte concernente às coisas. Os Projetos e os autores citados, dentro da nova concepção jurídica dos títulos de crédito, colocam-se sem dúvida sob o ponto de vista segundo o qual o direito é tido como incorporado ao título e despersonalizado, considerado um bem, um valor, distinto da relação econômica de do, considerado um "submetido, portanto, às regras da çrculação dos bens móveis e não mais àquelas relativas à circulação dos direitos”. $\mathrm{Na}$ expressão do ilustre ASCARELLI (Teoria Geral dos Títulos de Crédito) "a circulação dos títulos de crédito tem como objeto imediato o título (e não o direito nêle inscrito)", e acrescenta que é em conseqüência da aquisição do direito real sôbre o título que o portador adquire o direito nêle mencionado.

Os institutos jurídicos, embora muitas vêzes reagindo à orientação ditada pelo desenvolvimento e aspectos novos dos fenômenos econômicos e sociais, têm de seguir o curso dos acontecimentos e se vão a pouco e pouco transformando pela necessidade de adatar-se às novas exigências. Por essa mesma consideração, deu o "Esbôço" preferência aos referidos Projetos no subordinar, ao contrário do Substitutivo, as sociedades comerciais à rubrica das pessoas. Pôsto seja o contrato a fonte da sociedade, esta interessa sôbre tudo pelas relações externas. E' sob êsse aspecto dinâmico e não sob o contratual, que apenas the marca a origem, que a sociedade se afirma no mundo jurídico. E como elucidam CASATI e RUSSO (Diritto Civile Italiano), foi pela predominância das relações externas das sociedades que os autores da nova codificação na Itália a subtraíram do Título relativo aos contratos. Foram, porém, menos felizes em incluí-las no Livro V Del Lavoro,

6 - R. F. D 
pois, entre outras objeções, é de observar-se que a sociedade é genuína expressão de uma economia capitalista e o seu regímen não pôde ser reduzido, sem tortura, ao âmbito do sistema jurídico do trabalho. (BOLAFFI, La società semplice).

No que concerne ao instituto da conta de participação, a sua inclusão no Livro relativo às pessoas explica-se naturalmente pelo fato de considerar-se sociedade comercial. Nesse caso, o "Esbôço" nada mais fêz do que adotar a orientação, aliás plausível, dos Projetos e do Substitutivo. O dott. OSCAR CAROSELLI, que na sua monografia L'associazone in participazione, inscrevendo-se entre os que consideram a participação uma simples relação de crédito, reconhece todavia prevalecer a corrente doutrinária que sustenta ser a participação uma sociedade. A essa concepção aderem, na Itália, MARGHIERI, VIDARI e FAGGELLA. Para VIVANTE, a participação tem estreita analogia com a sociedade. E a citada monografia alista ainda um grande número de juristas alemães que também sustentam que a participação é sociedade, entre outros, FLECHTHEIM, SAENGER, STAUB e WIELAND, para sòmente citar os mais modernos. Na França, a lei de 24 de junho de 1921 acabou por consagrar essa doutrina; e BONNECARRIERE e LABORDE, - LACOSTE, justificando a solução da lei francesa opinam no sentido de que a participação é veritable societé, pois pressupõe as prestações em dinheiro ou in natura e a participação nos lucros e nas perdas. Quer, porém, seja ela sociedade, ou associação, com ou sem personalidade jurídica, não poderia deixar de subordinar-se necessàriamente ao Título referente às sociedades, pela natural atração da matéria, em virtude de sua correlação, ou conexidade.

O Código Civil italiano classifica-a com associação e a inclui, como as sociedades e ao lado destas, no Livro del Lavoro.

\section{DOCOMÉR CIO (*)}

\section{Hernani Estrella}

1. Evolução. 2. Caracterização. 3. Fundamento racional. 4. Explicação científica. 5. Utilidade. 6. Conceito econômico. 7. Divisões e subdivisões. 8. Particularidades. 9. Condições existenciais.

1. - O estudo da marcha evolutiva do comércio assinala um dos aspectos mais atraentes da história da civilização humana. Indagar quando e onde irromperam as primeiras manifestações dessa atividade é problema que foge às cogitações do direito comercial. A êste interessa encará-la como produtora de certa ordem de relações, cujos efeitos define e regulamenta, na órbita jurídica. Mas, por que não seriam compreensíveis as suas prescrições sem o conhecimento da matéria que lhe serve de principal conteúdo, explica-se tratar do comércio quando se estuda a sua disciplina jurídica específica. E' segundo êsse método que o problema é pôsto nos livros e nos programas escolares. Por isso mesmo, não se vai para além da simples reafirmação de certa ordem de idéias, tomadas de empréstimo a outras disciplinas, às quais cabe estudá-lo sob prismas diversos. Assim, a história do comércio o descreve no tempo e no espaço, segundo as práticas seguidas entre os diversos povos $\left({ }^{1}\right)$; a história da civilização dêle se ocupa como expressão de cultura $\left({ }^{2}\right)$, ao passo que a economia examina-lhe a estrutura orgânica, diz das leis que lhe ditam o aparecimento e definem-lhe a função $\left({ }^{3}\right)$.

Mercê dos conhecimentos subministrados por estas disciplinas, se tem como averiguado que, já entre os povos da mais recuada antiguidade, era o comércio conhecido e praticado. As trocas in natura, for-

(*) Notas da primeira aula de Direito Comercial, professada no corrente ano letivo, Hist. del Com. GEORG SCBMTDT- - Hist, do conercio Mondial.

(2) BALEESTEROS GAIBROIS - Hist. de la Cultura, cap. XI. (2) BALLESTEROS GAIBROIS - Hist. de la Cultura, cap. XI.
(3) WEBER Trat. de Economia Polit. v. II, cap. XIX; VALENTI- Scienza 